18th of February, with the exception of having suffered from slight dysphagia and cough for the two previous days, but to these she paid no attention. At four o'clock the following morning she was awoke by sudden and great difficulty of breathing, which compelled her to assume the erect posture; there was a short hacking cough, with rigors and thirst.

She had never been similarly attacked. These symptoms increased somewhat during the day, when I was requested to see her at ten o'clock P.M. Her symptoms then were, orthopnœa; the respiration being very quick and laborious, with a dry cough, and an occasional croup-like inspiration; great anxiety of countenance; heat of skin; intense thirst; and rapid pulse. Pressure over the larynx caused pain; there were also present a feeling of constriction round the throat, and a very distressing sense of suffocation, similar (she said) to that of being partially smothered under hay, of which she could speak from recent experience. An internal examination of the throat assured me that it was healthy, and auscultation and percussion revealed a normal state of the thoracic viscera, with the exception of some harshness of the respiratory murmur, in consequence of the partly obstructed state of the rima glottidis. Twenty-four leeches were immediately applied to the region of the larynx; half a grain of tartarized antimony in solution was given every hour; and three grains of the chloride of mercury, combined with half a grain of opium, every third hour.

On the morning of the 20th, at nine A. M., I found her lying dow $n$ in bed, and very much relieved in every particular. The leeches had bled very freely: the antimony, for the first two or three doses, caused vomiting, but was afterwards retained, and she had expectorated a small quantity of extremely viscid mucus. I ordered the leeches to be re-applied, the bleeding to be encouraged by hot fomentations, and the medicines continued. In the evening she was going on favourably; gums slightly tender, from the calomel. Remedies as before.

On the morning of the 21 st she was much worse; all her previous symptoms had returned during the night. Her difficulty of breathing was very great; there was some vertigo; her extremities were becoming cold; her pulse thready; and she expressed her firm conviction that if not shortly relieved from her distress, she should soon die. I quite coincided in my patient's opinion, and thinking it unjustifiable to spend more time in the trial of remedies, as soon as possible $\mathrm{I}$ performed the operation of tracheotomy, by making an incision, of about half an inch in length, down to the trachea, just one inch above the sternum, and then passing in the tracheotomy trocar and canula. There was a little hæmorrhage from the integuments, but it soon ceased, (before the trachea was opened,) and a small quantity of frothy blood, which issued at first from the opening in the trachea, almost instantly stopped. The relief afforded by the operation was most marked; after recovering from its immediate effects, her breathing became perfectly calm and easy; her anxiety and distress of countenance, with the dread of suffocation, vanished the pnlse increased in power and volume, and she expressed herself as feeling "in heaven." From this moment she continued to improve, without an unfarourable svmptom.

On the 24th the tube was removed from the trachea; the opening, however, remained pervious for a period of from seven to ten days from the time it was made; it then gradually closed entirely. The gums hecame affected by the mercury, and were kept tender If, during three or four days after the operation, the free ingress of air to the lungs was prevented, by my finger being placed unobservedly over the tube or onenin-, ise patient immediately became aware $n f$ wilat was being done, and complained of diffieuity of breathing; but day by day the respiration improved when the opening was temporarily closed, until it finally became quite natural. Mrs. M- quite recovered.

This, like many other cases of a similar kind, shows how very snon laryngitis subsides when the passage of air over the inflamed surface is obviated, and free breathing is permitted by an opening below; and how desirable it is to afford that relief early, and before the general powers have suffered greatly by the continuance of distress.

April 5th, 1845.

\section{CHANGE OF PRESENTATION DURING LABOUR.}

By C. M. MruLEn, Esq. Claremont Terrace, Stoke Newington-road. I Loor upon the following case as particularly instructive to the student and young practitioner, in teaching them not to place too great a reliance upon the first presenting part of the foetus. On the 28th of November I was called, at three o'clock P.M., to Mrs. M during the whole night, but the pains had increased in severity during the last two hours, coming on every ten minutes; no discharge at all.
As I was obliged to see a patient at a distance, I thought it advisable to institute an examination, and found the os uteri about the size of a shilling, and dilatable; head presenting, and distinctly felt also through the parietes of the cervix; membranes entire. It being a first labour, and viewed by me as perfectly natural, I was under no apprehension, but visited my distant patient, and returned to Mrs. MI_— at five o'clock; hoping now to find her considerably advanced. I made another examination, but found the os very little more dilated. The pains recurred every quarter of an hour; head still presenting. Such being the case, I again left her, with the promise to return at twelve, which I did, but found very little improvement in the size of the os. The pains had ceased entirely for the last hour; I could still feel the head.

I now left her for the night, giving orders to the nurse to send for me in case of the pains returning with any degree of force or frequency, or the liquor amnii escaping. I was not, however, sent for until nine o'clock on the morning of the 29 th, the pains having come on at eight, and considerably increased in severity during the last half hour. I instituted another examination, and found, to my astonishment, not the head presenting, but the right elbow protruding nearly to the vulva, the head bent to the right side of the mother, and the child's ribs easily felt.

Of course my future proceedings were clear enough ; I introduced my hand, and with some little difficulty turned the child, and safely delivered the mother. The child was dead. With the exception of exhaustion, the mother has gone on very favourably hitherto. Now had this been the hand instead of the elbow, I should not have been surprised, as eases of this member coming down by the side of or before the head are not unfrequent; but here was a positive change of position taking place during the hours of cessation of pain.

Having thus described the case, I leave it to your numerous readers, some of whom may have met with a similar instance.

January, 1845 .

\section{DEATH FROM HEPATIC ABSCESS BURSTING INTO THE} PERICARDIUM.

By R. Allan, Esq. Staff Surgeon, Port Louis, Mauritius.

Cumia, aged thirty-five, native of Bombay, had been in Mauritius one year, working as a field-labourer, when he came into the Immigration Depôt, on the 21 st of December, 1844, for the purpose of entering into a new engagement, having walked seven or eight miles on that day. He remained in apparent good health until six o'clock on the morning of the 26 th, when he began to complain of pain at the pit of the stomach, and died at half-past ten A.M.

Sectio cadaveris twenty-one hours after death.-About two pints of reddish pus and serum within the pericardium, the entire of which membrane was slightly inflamed. On laying the pericardium freely open, thick yellowish-green pus was seen oozing from an aperture large enough to admit the finger, which led through the diaphragm into an abscess in the smaller lobe of the liver, capable of containing a pint of fluid.

It is probable that the pus of the hepatic abscess had been oozing into the sac of the pericardium during some hours before death, causing inflammation, and then annihilating the heart's action by pressure.

Messrs. Rogers and Powell.surmouns, were present with me at the dissantion, and we have forwarded the parts to the Military Museum at Chatham.

Port Louis, Mauritius, Feb, 4th, 1845.

\section{PARTIAL ADHESION OF PLACENTA OVER OS UTERI, WITH} FOOT AND UMBILICAL CORD PRESENTING.

By James French, Esq. Surgeon, Nantwich.

ON Wednesday, April 16th, 1845, I was summoned to attend Mrs. P-, aged thirty-six, strong and healthy. She had previously given birth to three children, and had always natural and quick labour. She considered herself to be between the eighth and ninth month of pregnancy. When I saw her, at three P.M., she had slight pains, accompanied with hæmorrhage, which she told me she had occasionally had for six weeks previously. I at once considered it to be a case of placental presentation. On examination, I found the os uteri dilated to the size of a crownpiece, with a portion of the placenta projecting over about onethird of it, and adhering to the left side. From the continued hæmorrhage I ruptured the membranes, and found the umbilical cord and left foot presenting. The hæmorrhage ceased, as did the pains, and she fell asleep.

At seven P.M. she had several stronger pains, and on a second examination $I$ found the left foot, with the umbilical cord twisted 